Israel. Development was assessed before treatment and cognitive outcomes were determined after 6 to 21 years and analyzed in relation to treatment lag (after 1 month from onset) and pretreatment regression. Cognitive outcome was normal in all $22(100 \%)$ infants treated within 1 month of onset of infantile spasms (early treatment group), and in $40 \%$ of 15 treated after 1 to 6.5 months (late-treatment group). Normal cognitive outcome occurred in all 25 $(100 \%)$ with no or mild mental deterioration at onset, but in only $3(25 \%)$ of 12 with severe pre-treatment deterioration. The prognosis for normal long-term cognitive outcome is poor if development has severely regressed for 1 month or more before treatment begins. (Kivity S, Lerman P, Ariel R et al. Long-term cognitive outcomes of a cohort of children with cryptogenic infantile spasms treated with high-dose adrenocorticotropic hormone. Epilepsia March 2004;45:255-262). (Reprints: Dr S Kivity, Pediatric Epilepsy Unit \& EEG Laboratory, Schneider Children's Medical Center of Israel, Petah Tiqva, 49202, Israel).

COMMENT. In this series of cryptogenic cases, infantile spasms were permanently controlled in $92 \%$ of the early treated group and in $80 \%$ of the late treated group. Adverse effects were common with the high dose ACTH regimen: Cushingoid features developed in $100 \%$, hypertension in $>50 \%$, and hypokalemia and infections were frequent occurrences. The authors justify the high-dose ACTH based on the results of a previous study showing poor results in patients treated with low-dose ACTH or corticosteroids (Lerman P, Kivity S. J Pediatr 1982;101:294-6).

The debate regarding low vs high dose ACTH for infantile spasms continues. My own preference like that of researchers in Japan has been for the low dose regimen, so that serious side effects are avoided (Millichap JG, Bickford RG. JAMA 1962;182:523-7; Ito M et al. Pediatr Neurol 1990;6:240-4). High doses are favored by colleagues in the UK and also by some in the US (Snead OC, et al. Neurology 1989;39:1027-31). The earlier diagnosis is made and ACTH treatment begun, the better the results. This is true with either regimen. Whether the incidence of relapse is less and cognitive outcome superior with large dose cf low dose treatment remains to be proven by a controlled trial.

\title{
COGNITIVE OUTCOME OF HEMISPHERECTOMY
}

Long-term neuropsychological outcome was studied in 71 children who underwent hemispherectomy for severe and intractable seizures at the Johns Hopkins Hospital between 1968 and 1997. The cause of the seizures was cortical dysplasia in 27, Rasmussen syndrome in 37 , and vascular malformation or stroke in 7. Mean age at surgery was 7.2 years. Seizures were completely controlled in $65 \%$ at average follow-up of 5.4 years, and $49 \%$ had discontinued medications. Mean IQ correlated with seizure etiology: 70s for Rasmussen and vascular patients, and 30s for cortical dysplasia patients. No significant change in cognitive measures occurred between surgery and follow-up. (Pulsifer MB, Brandt J, Salorio CF, et al. The cognitive outcome of hemispherectomy in 71 children. Epilepsia March 2004;45:243254). (Reprints: Dr MB Pulsifer, Massachusetts General Hospital, Harvard Medical School, 5 Emerson Place, Suite 105, Boston, MA 02114).

COMMENT. Cognitive outcome in children with hemispherectomy for seizures is correlated with seizure etiology, patients with cortical dysplasia having lowest scores in intelligence and language while visual motor skills are relatively spared. 